\title{
Estimating the energetic cost of feeding excess dietary nitrogen to dairy cows
}

\author{
K. F. Reed, ${ }^{* 1}$ H. C. Bonfá,† J. Dijkstra,ł D. P. Casper,§ and E. Kebreab\# \\ *US Dairy Forage Research Station, USDA-Agricultural Research Service, 1925 Linden Dr., Madison, WI 53706 \\ †Department of Animal Science, Universidade Federal de Viçosa, Viçosa, Brazil 36570-000 \\ ¥Animal Nutrition Group, Wageningen University and Research, PO Box 338, 6700 AH Wageningen, the Netherlands \\ §Furst-McNess Company, 120 East Clark St., Freeport, IL 61032 \\ \#Department of Animal Science, University of California, Davis 95616
}

\section{ABSTRACT}

Feeding $\mathrm{N}$ in excess of requirement could require the use of additional energy to metabolize excess protein, and to synthesize and excrete urea; however, the amount and fate of this energy is unknown. Little progress has been made on this topic in recent decades, so an extension of work published in 1970 was conducted to quantify the effect of excess $\mathrm{N}$ on ruminant energetics. In part 1 of this study, the results of previous work were replicated using a simple linear regression to estimate the effect of excess $\mathrm{N}$ on energy balance. In part 2, mixed model methodology and a larger data set were used to improve upon the previously reported linear regression methods. In part 3, heat production, retained energy, and milk energy replaced the composite energy balance variable previously proposed as the dependent variable to narrow the effect of excess N. In addition, rumen degradable and undegradable protein intakes were estimated using table values and included as covariates in part 3. Excess $\mathrm{N}$ had opposite and approximately equal effects on heat production $(+4.1$ to $+7.6 \mathrm{kcal} / \mathrm{g}$ of excess $\mathrm{N})$ and retained energy $(-4.2$ to $-6.6 \mathrm{kcal} / \mathrm{g}$ of excess N) but had a larger negative effect on milk gross energy $(-52$ to $-68 \mathrm{kcal} / \mathrm{g}$ of excess $\mathrm{N})$. The results suggest that feeding excess $\mathrm{N}$ increases heat production, but more investigation is required to determine why excess $\mathrm{N}$ has such a large effect on milk gross energy production.

Key words: nitrogen, energetics, nutrient requirements

\section{INTRODUCTION}

The interactions between protein and energy in the ruminant animal are complex and have been the subject of extensive study (e.g., Oldham, 1984; Broderick,

Received January 12, 2017.

Accepted May 22, 2017.

${ }^{1}$ Corresponding author: kristan.reed@ars.usda.gov
2003; Rius et al., 2010). Although not entirely isolated from each other, protein-energy interactions can be divided into rumen and postrumen interactions. In the rumen, the ratio of rumen-degradable organic matter (RDOM) to RDP is an important factor determining microbial protein synthesis efficiency (Oldham, 1984; NRC, 2001). Oversupply of RDP for a given level of RDOM will result in low efficiency of microbial protein synthesis per unit of RDP. Conversely, if RDP is limiting, increasing RDOM will not increase microbial protein synthesis, resulting in a decrease in the efficiency of microbial protein synthesis per unit of RDOM (Bach et al., 2005). Further, increasing the CP content of the diet, in particular the RDP content, can increase the overall ration digestibility and increase the total ME (Mcal/ $\mathrm{kg}$ of DM) and MP content (g/ $\mathrm{kg}$ of DM; Oldham, 1984). The availability of AA in the rumen can also have an added stimulatory effect on microbial protein synthesis and fermentation in the rumen (Van Kessel and Russel, 1996; NRC, 2001), adding another layer of complexity to protein-energy interactions. Perhaps due to the influence of $\mathrm{CP}$ content on digestibility, DMI tends to increase with increasing CP content (Sinclair et al., 2014), leading to hypertrophy of the gastrointestinal tract and increased net absorption of nutrients (Oldham, 1984).

Postabsorptive protein-energy interactions are equally complex. As mentioned, an increase in $\mathrm{CP}$ content is often associated with an increase in DMI leading to an increase in total milk production. In addition, if the postrumen supply of AA is increased, the resulting increase in gluconeogenesis is greater than that which can be attributable to gluconeogenesis from the AA themselves (Oldham, 1984). This observation in addition to recent investigations into the influence of specific AA on milk protein synthesis (Appuhamy et al., 2011; Castro et al., 2016) suggest AA have signaling functions that influence metabolic pathways governing energy use and production. Most positive effects of increasing diet CP occur when CP intakes are low, whereas high levels of 
$\mathrm{CP}$ intake can have negative effects on energy use and milk production efficiency (Broderick, 2003).

In spite of the large body of literature dedicated to energy and protein requirements in lactating dairy cows, quantifiable information is still lacking about the effect of excess protein on energy use efficiency. Tyrrell et al. (1970) found that an excess $\mathrm{N}$ balance had a negative effect on the energy balance of lactating dairy cows, on the order of $13(13.3 \pm 1.2$, Table 2$)$ kcal of digestible energy (DE) per g of $\mathrm{N}$ fed over requirement. The use of $\mathrm{N}$ instead of protein, in this case, emphasizes that nonprotein $\mathrm{N}$ sources such as urea and AA influence energy use along with true protein, and that their investigation did not distinguish between the different forms of dietary N. Since the investigation by Tyrrell et al. (1970), little progress has been made in the effort to define or quantify this relationship. Administration of $\mathrm{NH}_{4}^{+}$was shown to increase liver $\mathrm{O}_{2}$ consumption more (2- to 8-fold) than theoretical estimates of $\mathrm{O}_{2}$ consumption required for ureagenesis (Milano et al., 2000). However, Reynolds et al. (1991) found liver $\mathrm{NH}_{3}-\mathrm{N}$ removal increased, whereas liver $\mathrm{O}_{2}$ consumption stayed the same when a forage-based diet was fed to growing heifers compared with an iso-nitrogenous, iso-energetic concentrate-based diet. Similarly, Ferrell et al. (2001) found that supplementing a high-concentrate diet with protein- $\mathrm{N}$ increased hepatic $\mathrm{O}_{2}$ consumption compared with the control and urea-N supplementation. Thus, evidence also suggests that the value reported by Tyrrell et al. (1970) overestimates the energy required to excrete excess $\mathrm{N}$ and this value varies with the form of dietary $\mathrm{N}$.

In the past, feeding systems based on TDN have used a fixed value for the loss of protein energy in urine (1.55 $\mathrm{kcal} / \mathrm{g}$ of protein), which was subtracted from protein's heat of combustion $(5.65 \mathrm{kcal} / \mathrm{g}$ of protein) so that the contribution of protein to TDN was equivalent to that of carbohydrate $(4.1 \mathrm{kcal} / \mathrm{g}$ of carbohydrate; Maynard, 1953). The NRC (1988) briefly mentioned overfeeding $\mathrm{N}$ may have an additional energetic cost based on the work of Tyrrell et al. (1970); however, the effect was considered minor and was not included in the final model. The most recent edition does not account for the loss of energy in urine in its estimation of TDN and does not mention the effect of overfeeding $\mathrm{N}$ on energetics at all (NRC, 2001).

To determine the effect of feeding excess $\mathrm{N}$ on the net energy retained in milk and meat products, the energy retained in tissue (RE) and lost as heat must be quantified. Because RE is difficult to measure, 2 indirect methods for estimating RE have been developed. The first method uses gas exchange measurements of $\mathrm{O}_{2}$ consumption and $\mathrm{CO}_{2}$ and $\mathrm{CH}_{4}$ production to calculate heat production $(\mathbf{H P})$ with an empirical equation: most commonly the Brouwer equation (Brouwer, 1965) with or without the energetic adjustment for protein catabolism correcting for urinary $\mathrm{N}$ (UN) loss. In this method, $\mathrm{RE}$ is estimated as the difference between energy intake and the loss of energy via excretion, secretion, and HP. The second method uses the $\mathrm{C}-\mathrm{N}$ balance of the animal, and assuming all retained $\mathrm{C}$ and $\mathrm{N}$ is in protein or fat, estimates RE based on the energy contained in those nutrient pools (Brouwer, 1965). Heat production is then estimated as the difference between energy intake, RE, and excreted energy.

To determine the effects of excess $\mathrm{N}$ balance on energy balance (EB), Tyrrell et al. (1970) defined EB as the sum of RE and milk gross energy (MGE). The $\mathrm{EB}$ was regressed on energy intake (EI) in the form of $\mathrm{DE}$ or ME, metabolic body weight (MBW), DE or $\mathrm{ME}$ content of the feed (EC), and the amount of $\mathrm{N}$ fed above requirement $(\mathbf{E x} \mathbf{N})$ in a single multiple regression model. They reported when lactating dairy cows were in a positive $\mathrm{N}$ balance $(\mathrm{ExN}>0)$, ExN had a negative effect on EB. However, the data set contained only 350 observations and did not use a mixed-model methodology to account for random effects of individual animals or studies. Regression coefficient and standard error estimates from analyses of multi-study data that do not account for the effect of study have been shown to be biased (St-Pierre, 2001). Accounting for the random effect between studies (and animals) in this case could result in a change in the magnitude of the relationship between ExN and energy use, increase the confidence in those estimates, or both. The objective of this investigation was to re-evaluate the approach reported by Tyrrell et al. (1970) using a larger and more robust data set in conjunction with a cross-classified mixed model framework to quantify the effect of ExN on dairy cow energetics. In addition, because energy balance is the sum of disparate energy processes, the effect of ExN on energy transfer to heat, tissue deposition, and milk was also investigated. It was hypothesized that the influence of ExN on EB is predominantly due to an increase in HP and not a decrease in RE or MGE. Further, the additional variables of RDP and RUP supply were included in models to investigate the hypothesis that different forms of $\mathrm{N}$ do not have the same influence on energy use.

\section{MATERIALS AND METHODS}

\section{Modeling Framework}

This study was designed to replicate and extend the work proposed by Tyrrell et al. (1970) in 3 parts. In part 1, the results of Tyrrell et al. (1970) were replicated by limiting the data to observations collected before 
$1970(\mathrm{n}=330)$ and fitting the simple linear regressions described in their study using the following model:

$$
Y_{i}=\mathbf{X}_{i}^{T} \boldsymbol{\beta}+\varepsilon_{i},
$$

where $Y_{i}$ is the $i$ th observation of the dependent variable energy balance, $\boldsymbol{\beta}$ is the vector of parameters, $\mathbf{X}_{i}^{T}$ is the transpose vector of the $i$ th observation of independent variables, and $\varepsilon_{i}$ is the residual error of the $i$ th observation. The independent variables used included EI (Mcal/d), MBW $\left(\mathrm{kg}^{0.75}\right)$, energy content of the feed (EC in either DE or ME, Mcal/kg of DM), and ExN $(\mathrm{g} / \mathrm{d})$.

In part 2, the framework described by Tyrrell et al. (1970) was extended by designating a mixed-model error structure, including a cross-classified random effect of animal and study, and fitting the model to all available observations while preserving the dependent variable and fixed effects originally designated by Tyrrell et al. (1970). In part 3, different dependent variables were investigated to narrow the effect of ExN on energy balance to HP, tissue energy balance, or MGE production. Heat production estimates were calculated using the Brouwer (1965) equation corrected for UN (HPRQ) and uncorrected for UN (HPUN) to investigate the magnitude of the effect of UN on HP. Tissue energy balance estimates were based on both the C-N balance method (TEBCN) and the gas exchange method (TEBRQ). A model base from a set of 16 potential explanatory variables describing energy intake, energy content, BW, and production in different units was selected for each of the 5 dependent variables in an effort to retain the biological information of the fixed effects proposed by Tyrrell et al. (1970), while reducing model multicollinearity. For example, a base model with DMI, $\mathrm{MBW}$, and EC would still retain information about intake, BW, and the energy in the diet but would reduce the collinearity of a model with EI and EC. After the base model was defined, the effect of variables linked to protein intake and metabolism, specifically ExN, RDP, and RUP, were investigated for their effect on HP, tissue energy balance, and MGE.

\section{Database}

The compiled data set used for model development contained 1,110 indirect calorimetry observations from 64 experiments conducted at the USDA Energy and Metabolism laboratory in Beltsville, Maryland. Calorimetry studies that evaluated hormonal therapy or did not report diet composition were excluded from this analysis. The data set is composed of individual daily nutrient balance and indirect calorimetry observations from lactating dairy cows and contains a wide range of diet ingredients and compositions (Table 1). Feces were collected from chambers on a regular basis and washed for residual fecal matter at the end of the trial. To quantify relationships, total collection of urine is required (Spek et al., 2013), and in the present data set urine was collected through bladder catheters. For additional supporting information about the data set see Moraes et al. (2014).

The EB (Mcal/d) variable used in parts 1 and 2 was estimated according to the following formula:

$$
\begin{aligned}
\mathrm{EB} & =\mathrm{MGE}+1_{\mathrm{TEBRQ}>0}(1.14 \times \mathrm{TEBRQ}) \\
& +1_{\mathrm{TEBRQ}<0}(0.84 \times \mathrm{TEBRQ})
\end{aligned}
$$

as described by Tyrrell et al. (1970), where $1_{\mathrm{X}}$ is the indicator function including the term when the conditions of $\mathrm{X}$ are true and excluding the term when it is false. The difference between supply and requirement was used to create a variable describing the amount of ExN, or $\mathrm{N}$ fed above the predicted requirement. Nitrogen requirements for part 1 were estimated according to Tyrrell et al. (1970) as follows:

$$
\mathrm{N}_{\text {req }}(\mathrm{g} / \mathrm{d})=0.456 \times \mathrm{MBW}+1.60 \times \mathrm{N}_{\text {Milk }}+45 \times \mathrm{E}_{\mathrm{PRC}} \text {, }
$$

where MBW $\left(\mathrm{kg}^{0.75}\right)$ is $\mathrm{BW}^{0.75}, \mathrm{~N}_{\text {Milk }}(\mathrm{g} / \mathrm{d})$ is the $\mathrm{N}$ in milk, and $\mathrm{E}_{\mathrm{PRC}}(\mathrm{Mcal} / \mathrm{d})$ is the energy deposited in the products of conception. Nitrogen requirements for parts 2 and 3 were estimated according to NRC (2001). Briefly, for parts 2 and 3, N requirements for maintenance, milk production, and pregnancy were estimated from BW, DMI, digestible nutrient intake, days in pregnancy, and measured milk $\mathrm{N}$ production. Calf weight was not available in the data set so $\mathrm{N}$ requirements for pregnancy in parts 2 and 3 were estimated as an exponential function of days in pregnancy according to recommendations of NRC (1988). The function for $\mathrm{N}$ requirements for pregnancy used in parts 2 and 3 differs slightly from that used by Tyrrell et al. (1970) and in part 1 of this study. Nitrogen supply for all 3 parts was calculated as the difference of $\mathrm{N}$ intake and fecal $\mathrm{N}$. The ExN variable was then used to subset the data to those observations that exceeded the requirements for $\mathrm{N}(\mathrm{ExN}>0 \mathrm{~g} / \mathrm{d})$ and those below requirements for $\mathrm{N}$ $($ ExN $<0 \mathrm{~g} / \mathrm{d})$. Tabular values of the rumen soluble, rumen degradable, and undegradable protein fractions, the rates of degradation $\left(\mathrm{k}_{\mathrm{d}}\right)$, and the rates of passage $\left(k_{p}\right)$ for each ingredient were used to estimate dietary RDP and RUP intake for each observation (NRC, 2001). Diet ingredient composition for $98 \%$ of DMI was required for RDP and RUP estimation resulting in a 
reduced data set for part 3 of 641 observations. Although some bias in RDP and RUP estimates from the methods presented by NRC (2001) exist (Bateman et al., 2005; Roman-Garcia et al., 2016), they are widely known and commonly used for diet formulation.

\section{Model Development}

The following cross-classified random effects model was used to explain the dependence of records originating from the same animal and study for parts 2 and 3 :

$$
Y_{i j k}=\mathbf{X}_{i j k}^{T} \boldsymbol{\beta}+a_{i}+s_{j}+\varepsilon_{i j k},
$$

where $Y_{i j k}$ is the $k$ th observation of EB, HPUN, HPRQ, TEBCN, TEBRQ, or MGE from the $j$ th study and the $i$ th animal; $\mathbf{X}_{i j k}^{T}$ is the transpose vector of explanatory variables; $\boldsymbol{\beta}$ is the vector of fixed effect parameters; $a_{i}$ is the random effect associated with the $i$ th animal; $s_{j}$ is the random effect associated with the $j$ th study; and $\varepsilon_{i j k}$ is the residual error assumed to be independent and identically distributed as $N\left(0, \sigma^{2}\right)$, where $\sigma^{2}$ is the residual variance. Further, $a_{i}$ and $s_{j}$ were assumed to be independent and distributed as $a_{i} \sim N\left(0, \sigma_{a}^{2}\right)$ and $s_{j} \sim N\left(0, \sigma_{s}^{2}\right)$, where $\sigma_{a}^{2}$ is the between-animal variance and $\sigma_{s}^{2}$ is the between-study variance. All mixed models were fit using the lme4 package in $\mathrm{R}$ statistical software (Bates et al., 2013).

Models in part 3 were fit using a systematic procedure to identify a base model that reduced multicollinearity from the models proposed by Tyrrell et al. (1970) followed by an investigation of the fixed effects related to $\mathrm{N}$ metabolism. Different units were investigated to describe intake [DMI, $\mathrm{kg} / \mathrm{d}$; DMI per unit of BW, $\mathrm{kg} /(\mathrm{d} \cdot \mathrm{kg}$ of $\mathrm{BW})]$, or energy intake (Mcal/d), energy content (DE content, Mcal $/ \mathrm{kg}$ of $\mathrm{DM}$; or $\mathrm{ME}$ content, Mcal/kg of DM), BW (kg; or MBW, $\mathrm{kg}^{0.75}$ ), and production (milk, kg/d; or milk GE, Mcal/d). All possible base models were fit using maximum likelihood estimation for the purpose of model selection and then fit with restricted maximum likelihood for reporting. The base model with the lowest Akaike information criterion was selected for each dependent variable and then the degree of multicollinearity was evaluated using the condition index of the fixed effects model. Condition indices were evaluated using the perturb package of R software (Hendrickx, 2012), which recommends a condition index $\leq 30$ (Belsley, 1991). Variables with the highest variance inflation factors were removed until the condition indices of the base models were less than 30 .

Table 1. Units, mean, SD, and range of variables used for covariate selection

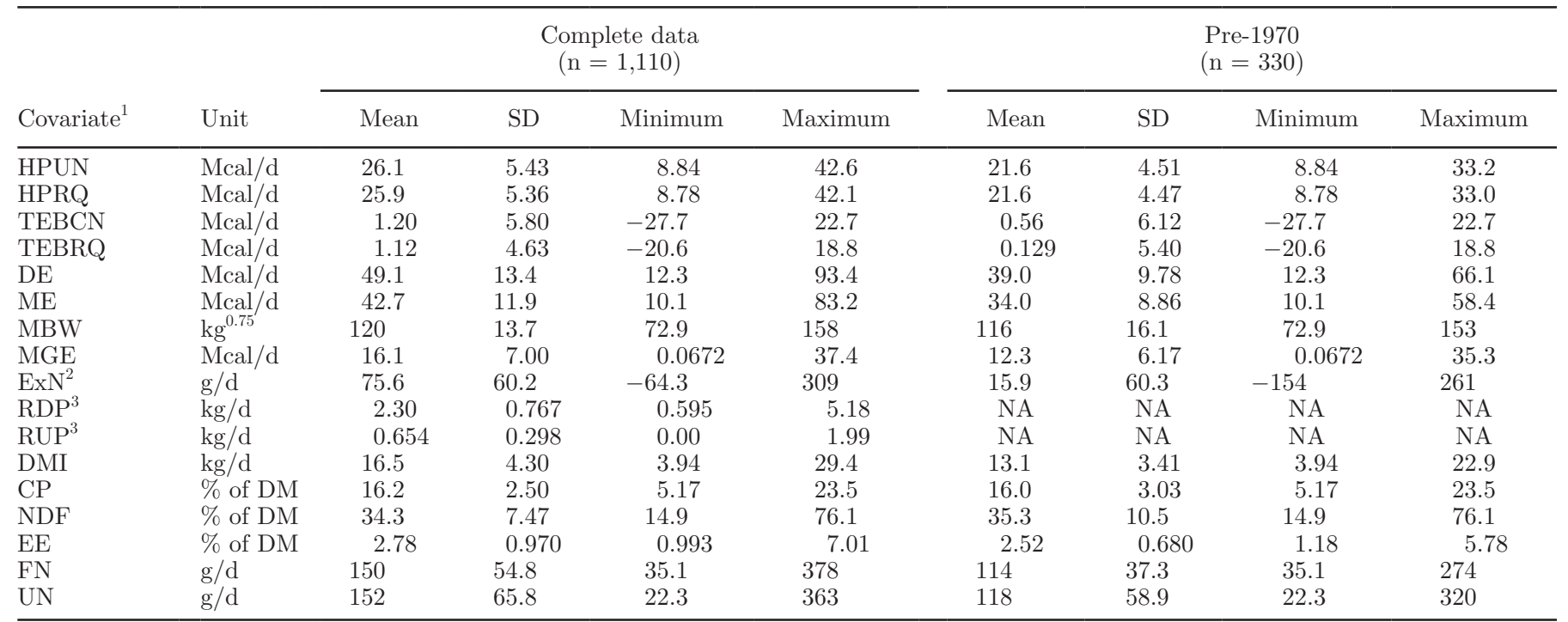

${ }^{1}$ Heat production uncorrected for urinary N (HPUN), heat production corrected for urinary N (HPRQ), tissue energy balance estimated by the respiratory quotient method (TEBRQ), tissue energy balance estimated by the carbon-nitrogen balance method (TEBCN), digestible energy intake per day (DE), metabolizable energy intake per day (ME), metabolic body weight (MBW), milk gross energy (MGE), N fed above or below requirement $(\mathrm{ExN})$, ether extract (EE), fecal $\mathrm{N}(\mathrm{FN})$, and urinary $\mathrm{N}(\mathrm{UN})$.

${ }^{2}$ ExN was estimated as the difference between digestible $\mathrm{N}$ intake and $\mathrm{N}$ requirement where digestible $\mathrm{N}$ intake was estimated as the difference between $\mathrm{N}$ intake and fecal $\mathrm{N}$. Nitrogen requirement was estimated using separate protocols for the complete data used in parts 2 and 3 and the data collected before 1970 used in part 1, which led to different ranges for this variable.

${ }^{3}$ Information required to estimate RDP and RUP using NRC (2001) table values for protein content was available for 641 observations. Both RDP and RUP were not calculated for the pre-1970 subset (NA). 
Variables related to $\mathrm{N}$ metabolism were $\operatorname{ExN}(\mathrm{g} / \mathrm{d})$, RDP $(\mathrm{kg} / \mathrm{d})$, and RUP $(\mathrm{kg} / \mathrm{d})$. A likelihood ratio test based on the chi-squared test statistic was used to determine significance $(P<0.05)$ of each of the $\mathrm{N}$ related variables. Residual analyses were carried out to test model assumptions through visual assessment of QQ-plot, plots of predicted versus observed values, and plots of residuals versus centered predicted values. Presence of model bias was evaluated through regression of predicted versus observed and residuals versus centered predicted plots.

\section{RESULTS}

Estimates of RDP and RUP indicate the diets in this data set have a relatively high RDP as a proportion of $\mathrm{CP}$ (mean $=0.78 \mathrm{~kg}$ of $\mathrm{RDP} / \mathrm{kg}$ of $\mathrm{CP}$ ) with values that ranged from 0.65 to $0.90 \mathrm{~kg}$ of $\mathrm{RDP} / \mathrm{kg}$ of $\mathrm{CP}$. Nitrogen balance estimates (ExN) had a mean of 75.6 $\mathrm{g}$ of $\mathrm{N} / \mathrm{d}$ and ranged from -64.3 to $309 \mathrm{~g} / \mathrm{d}$ for the complete data set, which is a positive shift of approximately $60 \mathrm{~g} / \mathrm{d}$ from the estimates for the pre-1970 data that had a mean of $15.9 \mathrm{~g} / \mathrm{d}$ and ranged from -154 to $261 \mathrm{~g} / \mathrm{d}$ (Table 1). This discrepancy is a reflection of the change in methods for estimation of $\mathrm{N}$ requirements used in the ExN calculation. The primary difference in the requirement estimates is that methods used by Tyrrell et al. (1970) use a scalar multiplier of MBW to estimate maintenance requirements, whereas the NRC (2001) methodology for estimating maintenance $\mathrm{N}$ requirements takes into account $\mathrm{BW}$, DMI, and fecal DM. Using the methods described by Tyrrell et al. (1970) to estimate ExN for the complete data results in the same range of ExN as the pre-1970 data but with a higher mean than the pre-1970 and a lower mean than estimates from the complete data with the updated requirement model $(31.7 \mathrm{~g} / \mathrm{d})$. This discrepancy in mean estimates of $\mathrm{ExN}$ indicates more of the studies of N-restricted diets $(\mathrm{ExN}<0)$ were conducted before 1970. Figure 1 shows the distribution of the ExN variable estimated for parts 2 and 3 with most observations ranging from 0 to $150 \mathrm{~g} / \mathrm{d}$.

The models developed by Tyrrell et al. (1970) are presented in Table 2 along with the current models developed in parts 1 and 2. Tyrrell et al. (1970) reported that ExN had a negative effect on EB for the group of observations in which $\mathrm{N}$ was fed in excess $(\operatorname{ExN}>0$, Equations [1] and [4]), irrespective of the energy unit (DE or ME). The results from part 1 qualitatively agree with Tyrrell et al. (1970) in that ExN had a negative effect on EB for ExN $>0$ (Equations [2] and [5]). However, when $\mathrm{N}$ supply did not meet requirements (ExN $<0)$, results from part 1 estimate a positive effect of ExN on EB (Equations [8] and [11]), which is in con- tradiction to insignificant results obtained by Tyrrell et al. (1970). In part 2, application of the mixed model framework and fitting to the full data set altered the results so that if energy was expressed in units of ME, ExN no longer had a significant effect on energy balance, regardless of $\mathrm{N}$ balance (Equations [6] and [12]). When energy was expressed as DE using the mixed model methodology in part 2, ExN had a negative effect on EB for ExN >0, and was not significant for ExN $<0$ (Equations [3] and [9]).

The results from part 3 are listed in Table 3. The original selected base models included ME intake for the HPUN and TEBRQ dependent variables and DMI for HPRQ and MGE dependent variables. Energy content was included in all initially selected base models but was removed to reduce multicollinearity. Removal of energy content from the model resulted in ME intake being included as the measure of intake for all dependent variables. Addition of $\mathrm{N}$ metabolism variables to the base model in part 3 showed that ExN is not a significant predictor of HPUN, HPRQ, or TEBRQ when the full data set was used (Equations [13], [16], [17], and [20]), but was included in all models predicting MGE and all other models fit with the high excess $\mathrm{N}$ data $(\mathrm{ExN}>0)$. Specifically, ExN has a positive effect on HP (HPUN and HPRQ; Equations [14], [15], [18], and [19]) and a negative effect on tissue energy balance (TEBRQ; Equations [21] and [22]) and MGE (Equations [23]-[26]). Rumen degradable protein had a positive effect on HPUN, HPRQ, and MGE (Equations [13], [15], [16], [19], [24], and [26]). Rumen undegradable protein was only found to be a significant positive predictor of HPRQ when the full data set was used and ExN was not included in the model (Equation [17]).

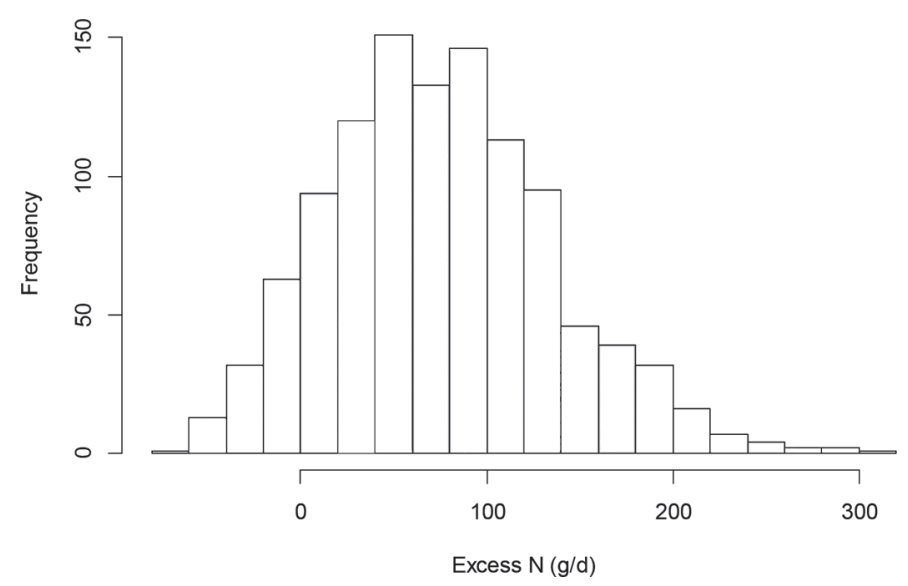

Figure 1. Histogram of the fed $\mathrm{N}$ above or below requirement (excess $\mathrm{N}, \mathrm{g} / \mathrm{d})$. A value of 0 indicates that supply ( $\mathrm{N}$ intake - fecal $\mathrm{N}$ ) matches estimated $\mathrm{N}$ requirement. 
ENERGETIC COSTS OF EXCESS DIETARY PROTEIN

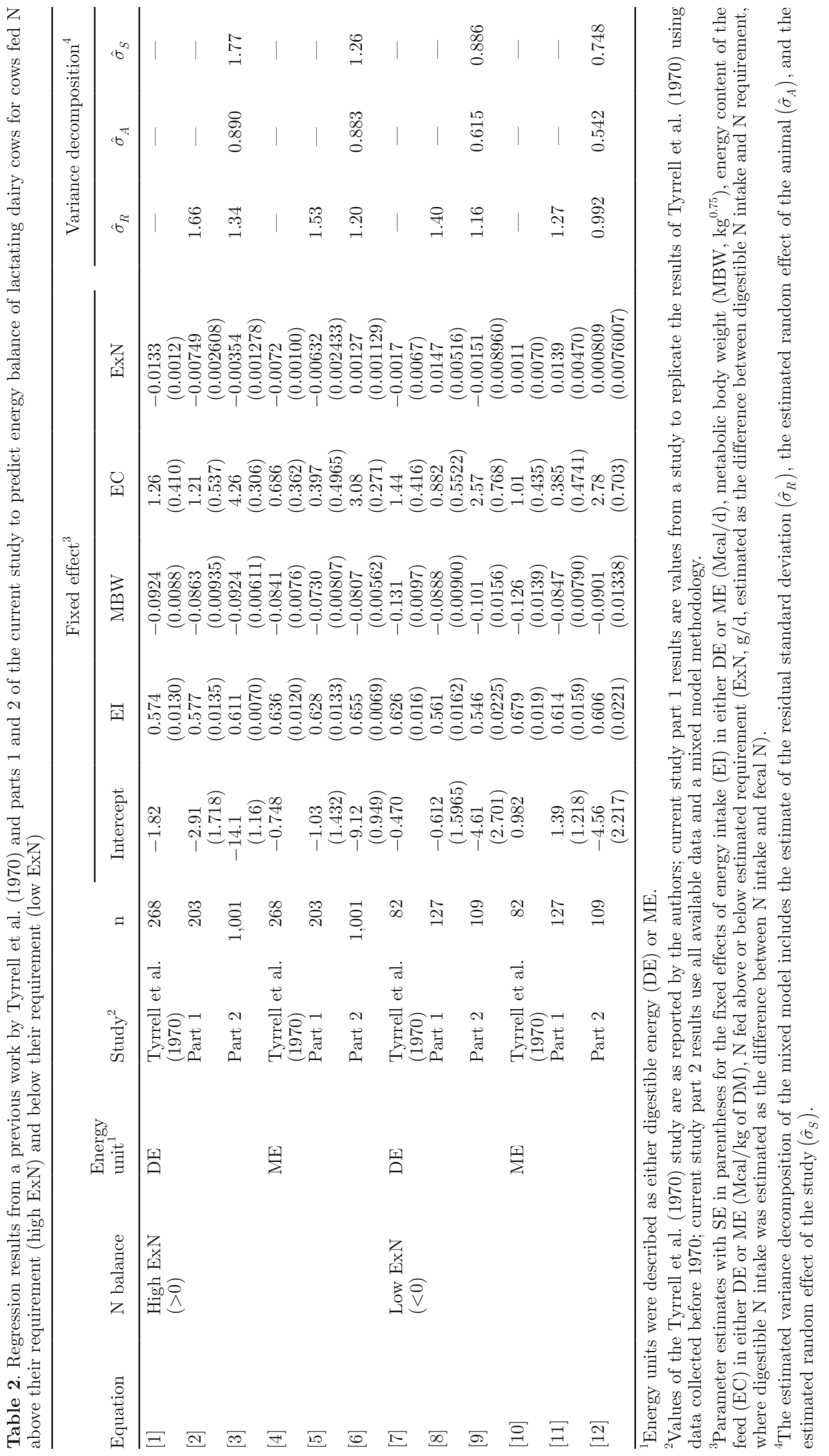




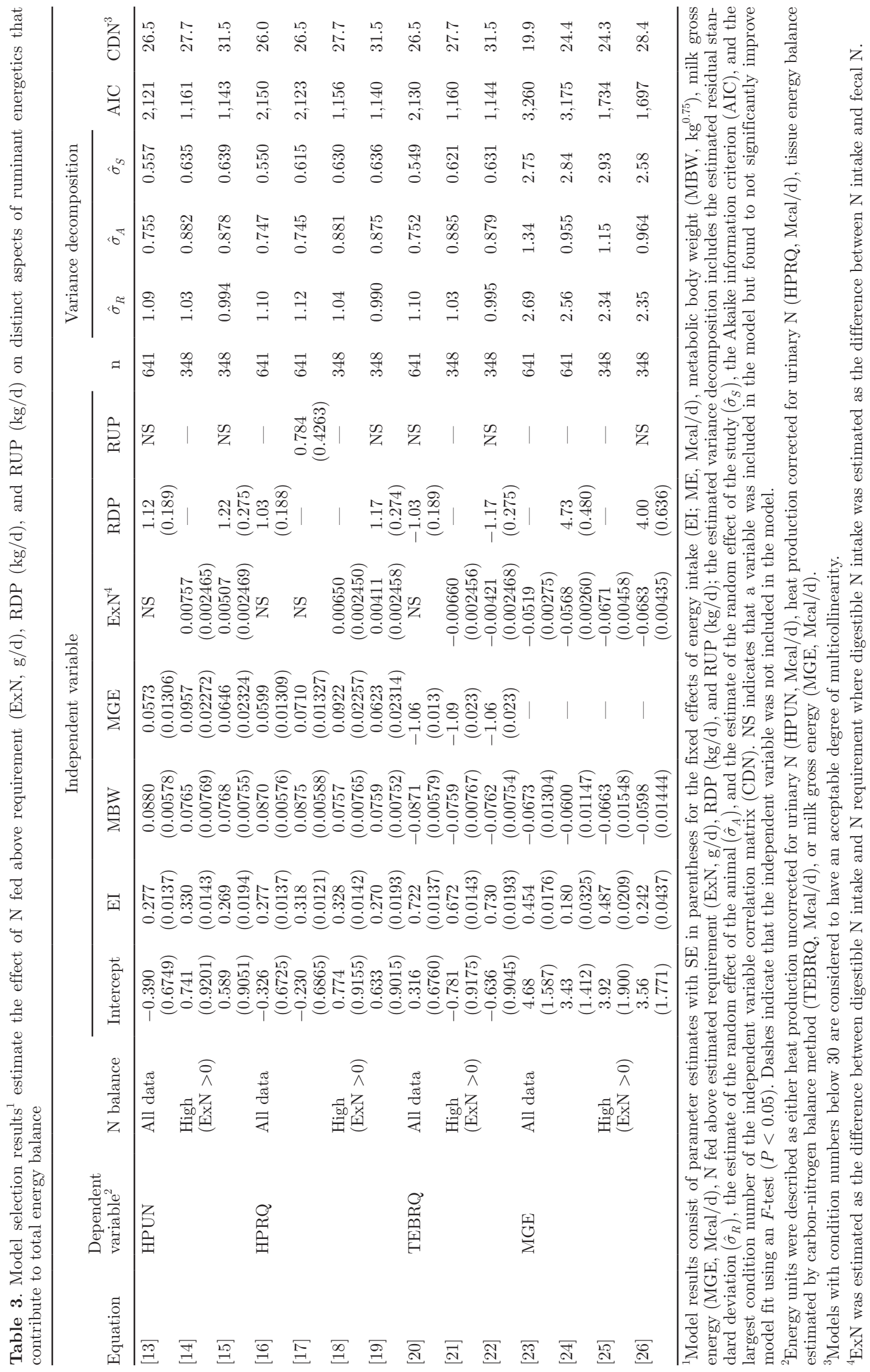


None of the $\mathrm{N}$ variables of interest were significant in predicting TEBCN (results not shown).

The condition number of 3 models (Equations [15], [19], and [22]) rose above the recommended cut off (30) for an acceptable degree of multicollinearity when RDP was included models with ExN in the restricted data set $($ ExN $>0)$. Residual analysis showed little to no deviation from the assumption of normality (Figure 2a and 2b). All residuals for Equations [13] to [22] follow the pattern illustrated in Figure 2a and 2e, and all residuals for Equations [23] to [26] follow the pattern illustrated in Figure 2b and 2f. Plots of the standardized residuals against the centered predicted values indicate a slight positive slope bias suggesting a tendency of the models to underpredict at higher values. However, plots of observed versus predicted values indicated no bias for all models (Figure 2b and 2c). Similar to the residual analysis, the observed versus predicted plots for Equations [13] to [22] follow the pattern illustrated in Figure 2c, and the plots for Equations [23] to [26] follow the pattern illustrated in Figure 2d.

\section{DISCUSSION}

Energy required to process and excrete $\mathrm{N}$ includes energy lost through metabolic transformations, synthesis of urea, and excretion by the kidneys. Of these, urea synthesis has received the most attention. The production of urea from ammonia requires the use of at least 4 high-energy bonds. If the $\mathrm{N}$ used to synthesize urea originates from an AA, deamination and regeneration of aspartate is thought to produce up to 6 high-energy bonds, making urea synthesis at least energetically neutral (Anand and Anand, 2010). However, Milano et al. (2000) found that increasing hepatic supply of $\mathrm{NH}_{3}-\mathrm{N}$ and subsequent urea production did not alter hepatic removal of AA, hypothesizing that both $\mathrm{N}$ atoms required for urea synthesis were supplied by $\mathrm{NH}_{3}$. In their study, the ratio of $\mathrm{NH}_{3}$ disappearance to urea- $\mathrm{N}$ appearance was not different than one, suggesting most, if not all, urea $\mathrm{N}$ can be supplied by $\mathrm{NH}_{3}$ in diets that deliver increasing levels of nonprotein $\mathrm{N}$ up to an additional supply of $10 \mathrm{~g}$ of nonprotein $\mathrm{N} / \mathrm{kg}$ of DM above a basal diet supply of $22 \mathrm{~g}$ of $\mathrm{N} / \mathrm{kg}$ of DM (Milano et al., 2000). Measuring HP during ammonia and urea infusion, Martin and Blaxter (1965) estimated $5.2 \mathrm{kcal}$ of heat was produced per $\mathrm{g}$ of $\mathrm{N}$ infused, attributing 3.8 kcal to production of urea from ammonia. Using a value of $22.1 \mathrm{kcal}$ of DE per mol of high-energy phosphate bond, this equates to the use of 4.8 high-energy bonds to produce urea from ammonia. However, the large number of metabolic pathways through which $\mathrm{N}$ compounds travel and variations in the extent of urea recycling prohibit exact biochemical estimation of the cost of metabolizing and excreting ExN. Regulation of urea transport across the rumen wall (Rojen et al., 2011), for example, decouples the extent of $\mathrm{N}$ recycling from $\mathrm{N}$ intake making the number of biochemical transformations that a N-containing molecule undergoes before excretion impossible to estimate at this time. Maltby et al. (2005) found that ureagenesis accounted for $<5 \%$ of liver $\mathrm{O}_{2}$ consumption when they measured hepatic $\mathrm{O}_{2}$ consumption in steers fed high-protein diets. Thus, the additional energy required for metabolizing and excreting $\mathrm{N}$ beyond the energy required for ureagenesis is likely the result of several different biochemical and metabolic processes.

In their regression study, Tyrrell et al. (1970) postulated the difference of $6.1 \mathrm{kcal} / \mathrm{g}$ of ExN between coefficients for ExN when EI was expressed as ME (Equation [4]) instead of DE (Equation [1]) was equivalent to the energetic cost of synthesizing urea from both ammonia and AA precursors. Using this logic, Tyrrell et al. (1970) hypothesized the additional energetic cost of excreting $\mathrm{N}$ was $7.2 \mathrm{kcal} / \mathrm{g}$ of ExN: the parameter estimate for the relationship between $\mathrm{ExN}$ and $\mathrm{EB}$ when EI was expressed as ME (Table 2). In the attempt to replicate the results of Tyrrell et al. (1970) in part 1, the difference in ExN parameter estimates when energy was expressed as DE versus ME was much smaller: a difference of $1.2 \mathrm{kcal} / \mathrm{g}$ of $\operatorname{ExN}$ (Equations [2] and [5]) compared with $6.1 \mathrm{kcal} / \mathrm{g}$ of ExN as estimated by Tyrrell et al. (1970; Equations [1] and [4]). This discrepancy in parameter estimates does not support the hypothesis that the coefficient for ExN when EI is expressed as ME represents an energetic cost of $\mathrm{N}$ metabolism beyond that which is excreted in urea. Further, when the full data set and a mixed model were employed in part 2, the coefficient for ExN when energy was expressed as ME was not significantly different from zero (Table 2, Equation [6]). Although the parameter estimate for the relationship of ExN with EB when energy was expressed as DE units in part 2 (Equation [3]) was still negative, it was smaller than the estimate from part 1 and the estimate reported by Tyrrell et al. (1970): $3.5 \mathrm{kcal} / \mathrm{g}$ of ExN, which is close to estimates of the energy required to synthesize urea proposed by Martin and Blaxter (1965). Results from part 2 suggest the energy required to metabolize ExN could be limited to the energy needed to synthesize and excrete urea because after urinary energy is accounted for in ME, ExN does not influence overall EB. Based on the results from part 2, nutrient requirement models that account for the loss of energy in urine would not need to make an additional adjustment for energy required to metabolize ExN. However, the energy lost in urine is not constant across diets and the average ratio of urinary energy:UN in the present data set is 
(a)

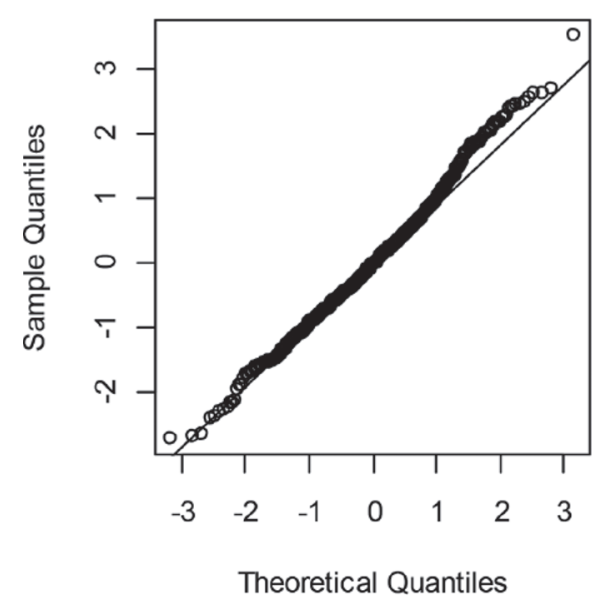

(c)

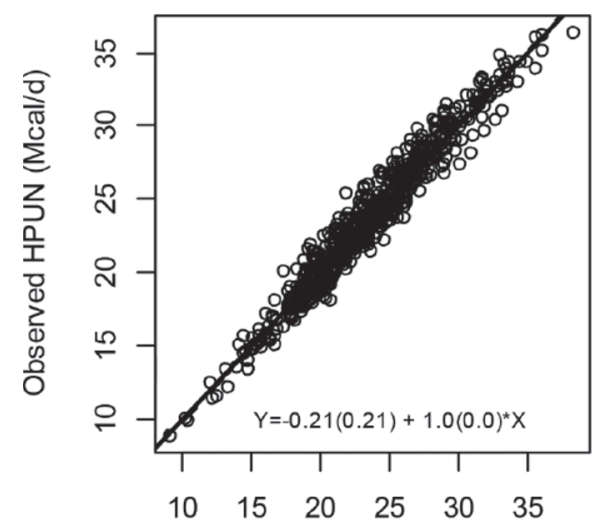

Predicted HPUN (Mcal/d)

(e)

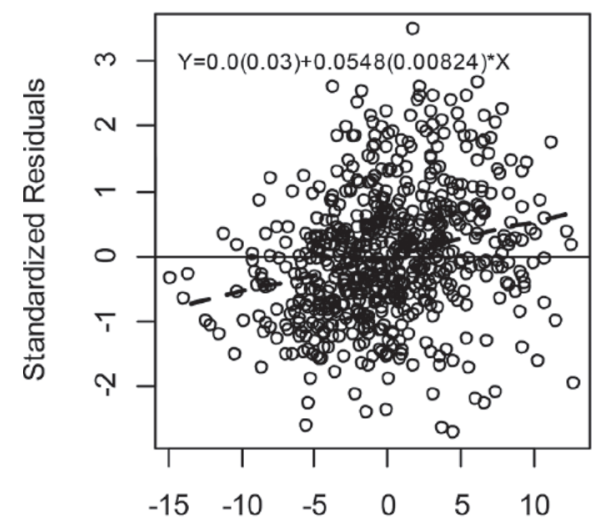

Centered Predicted HPUN (Mcal/d) (b)

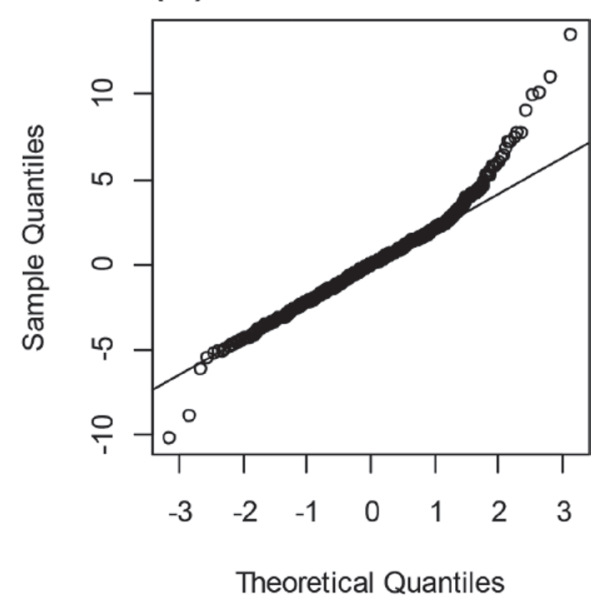

(d)

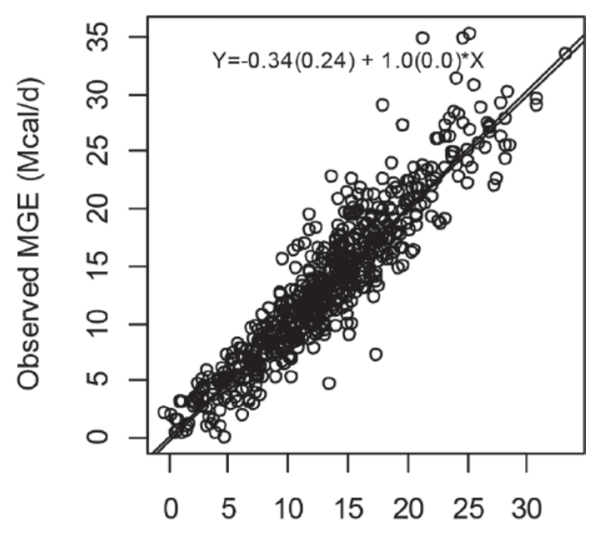

Predicted MGE (Mcal/d)

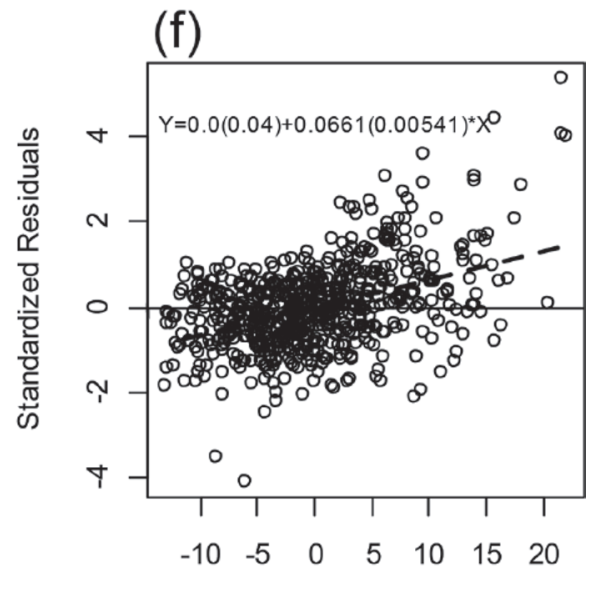

Centered Predicted MGE (Mcal/d)

Figure 2. (a) Quantile-quantile plot of heat production uncorrected for urinary N (HPUN, Mcal/d), (b) quantile-quantile plot of milk gross energy (MGE, Mcal/d), (c) scatter plot of the observed versus predicted HPUN (Mcal/d), (d) scatter plot of the observed versus predicted MGE (Mcal/d), (e) standardized residuals plotted against centered predicted values for HPUN, and (f) standardized residuals plotted against centered predicted values for MGE. In plots (c) and (d), the solid line indicates the line of unity, whereas in plots (e) and (f) the solid line indicates the x-axis. In plots (c), (d), (e), and (f), the dashed lines indicate the linear regression line of Y versus X, and the equation is the linear regression estimate with SE in parentheses. 
$17.1 \mathrm{kcal} / \mathrm{g}$ of $\mathrm{N}$, which is more than the urinary energy correction factor for protein that used to be included in estimation of TDN $(9.69 \mathrm{kcal} / \mathrm{g}$ of protein N; NRC, 1988). Thus, if ME is used as the measure of dietary energy content without a correction factor for the DE required to excrete ExN, an accommodation for the variable loss of energy in urine should be included in the calculation of ME.

The dependent variable used by Tyrrell et al. (1970) and in parts 1 and 2 is the sum of disparate energetic processes. By creating an aggregated response variable that includes both productive (RE, MGE) and nonproductive (HP) energy sinks, the model proposed by Tyrrell et al. (1970) masks potentially divergent effects of ExN on distinct uses of energy. To narrow the effect of ExN to a more specific point in energetic partitioning, the models fit in part 3 use the components of the EB sum as dependent variables. An increase in urea synthesis and $\mathrm{N}$ recycling would theoretically lead to an increase in HP, which is supported by the positive effect of ExN on HPUN and HPRQ, increasing HP between 4 and $8 \mathrm{kcal} / \mathrm{g}$ of ExN (Equations [14], [15], [18], and [19]), which is close to reported estimates for the energy required to synthesize and excrete urea (Martin and Blaxter, 1965).

However, energy required to metabolize $\mathrm{N}$ compounds as measured by $\mathrm{HP}$ and $\mathrm{O}_{2}$ consumption is variable depending on the source of N (Reynolds et al., 1991; Lobley et al., 1995; Ferrell et al., 2001). Although RDP and RUP are not direct reflections of the form of $\mathrm{N}$, they do reflect differences in the digestive and metabolic paths of feed N. In units of kilograms per day, RDP had a positive relationship with HP that ranged from 1.03 to $1.22 \mathrm{Mcal} / \mathrm{kg}$ of RDP (Equation [13], [15], [16], and [19]). Further, although RUP also had a positive effect on HP, it was smaller than that of RDP $(0.784 \mathrm{Mcal} / \mathrm{kg}$ of RUP vs. 1.03-1.22 Mcal $/ \mathrm{kg}$ of RDP), suggesting that more heat is produced per unit of RDP than per unit of RUP. This finding is also in alignment with what would be expected due the second law of thermodynamics because RDP is expected to undergo more digestive and metabolic transformation than RUP. However, factors not accounted for here such as the supply of both RDP and RUP with respect to their requirements and the AA profile will influence the number of heat-producing transactions that occur during each nutrient's course through an animal. In addition, because the dietary $\mathrm{CP}$ in the data set has relatively high proportions of RDP (and low proportions of RUP), further investigation into the relationships of RUP with HP and EB may be necessary to determine if the linear relationship estimated here holds over a higher range of RUP.

The dependent variables TEBRQ and TEBCN serve as an estimate of RE. Methods used to estimate RE through TEBCN included greater experimental error, which is reflected in the larger range and variance of this variable (Table 1) and is likely the reason no significant relationships were found with the $\mathrm{N}$ independent variables in part 3 . With a positive $\mathrm{N}$ balance $(\mathrm{ExN}>0)$, the negative effect of ExN on TEBRQ was between 4 and $7 \mathrm{kcal} / \mathrm{g}$ of ExN (Equations [21] and [22]), which is similar in magnitude to the effect of ExN on HP. Because the size of the effect of ExN on TEBRQ is similar to that of HP and because RE represents the energy retained in the animal after other energetic losses, such as HP, have been accounted for, this result suggests the influence of $\mathrm{ExN}$ on $\mathrm{RE}$ is due to an increase in HP. Similarly, the parameter estimates for the effect of RDP on RE (Equations [20] and [22]) were of comparable magnitude but opposite signs to the effects of RDP on HP, suggesting that this relationship may also be a result of the influence of RDP on HP.

Excess $\mathrm{N}$ had a strong negative effect on MGE (between -52 and $-68 \mathrm{kcal} / \mathrm{g}$ of ExN, Equations [23]-[26]), more than 3 times larger than the effect on the composite EB estimated by Tyrrell et al. (1970), and much larger than estimated costs of urea synthesis and excretion (Martin and Blaxter, 1965). Although increasing N content is associated with increasing intake, which can lead to an increase in milk production, the negative effect of ExN on MGE seen here does not contradict this observation because intake in the form of ME intake (EI) is already a covariate in the model. In addition, because ME intake was a covariate in the model, the effect of ExN on MGE can also not be attributable entirely to the loss of energy in urine. Very little information exists to explain why $\mathrm{N}$ fed above requirement reduces MGE. An abstract by Danfaer et al. (1980) reported a 4.5 Mcal decrease in MGE production of the diet when CP content was increased from 19 to $23 \%$, suggesting that this was roughly the cost of excreting $100 \mathrm{~g}$ of extra N; however, no other published information was found supporting this finding. Supply of AA or metabolizable AA was not accounted for in this study and could account for some of the unexplained variation. In addition, AA have been shown to have signaling functions on the mammary gland, affecting a change in milk production and potentially the efficiency of use of AA for lactation depending on the direction of the effect on production (Oldham, 1984; Appuhamy et al., 2011). Thus, the AA supply could influence the efficiency of milk production and have some part in the large negative relationship between ExN and MGE.

\section{CONCLUSIONS}

The quantification of energetic costs associated with excreting $\mathrm{N}$ when dairy cows are fed protein in 
excess of requirement can assist in refining the nutrient requirements of dairy cattle. These results suggest $\mathrm{N}$ fed above requirement increases $\mathrm{HP}$ and decreases RE and MGE. It is not clear why the relationships of ExN with MGE and RE appear to be of greater magnitude when estimated separately than when MGE and RE are combined into the composite dependent variable of EB. This apparent inconsistency in covariate estimates could be a result of the changing relationship of RE and MGE throughout the course of the lactation cycle. More investigation into this topic is needed to understand the biological mechanisms driving these relationships.

\section{ACKNOWLEDGMENTS}

The authors thank the University of California, Davis Sesnon Endowed Chair program, USDA NIFA Multistate Research Project NC-2040 and Ajinomoto Heartland (Chicago, IL) for their support of this project.

\section{REFERENCES}

Anand, U., and C. V. Anand. 2010. The energy cost of urea synthesis. Biochem. Educ. 21:198-199.

Appuhamy, J. A. D. R. N., A. L. Bell, W. A. D. Nayananjalie, J. Escobar, and M. D. Hanigan. 2011. Essential amino acids regulate both initiation and elongation of mRNA translation independent of insulin in MAC-T cells and bovine mammary tissue slices. J. Nutr. 141:1209-1215.

Bach, A., S. Calsamiglia, and M. D. Stern. 2005. Nitrogen metabolism in the rumen. J. Dairy Sci. 88 (E. Suppl.):E9-E21.

Bateman, H. G., J. H. Clark, and M. R. Murphy. 2005. Development of a system to predict feed protein flow to the small intestine of cattle. J. Dairy Sci. 88:282-295.

Bates, D., M. Maechler, B. Bolker, and S. Walker. 2013. lme4: Linear mixed-effect models using Eigen and S4. Vol. R package version 1.0-5. http://cran.r-project.org/web/packages/lme4/index.html.

Belsley, D. A. 1991. Conditioning diagnostics, collinearity and weak data in regression. John Wiley \& Sons, New York, NY.

Broderick, G. A. 2003. Effects of varying dietary protein and energy levels on the production of lactating dairy cows. J. Dairy Sci 86:1370-1381.

Brouwer, E. 1965. Report of sub-committee on constants and factors. In Proceedings of the 3rd Symposium on Energy Metabolism. K. L. Blaxter, ed. Academic Press, London, UK.

Castro, J. J., S. I. Arriola Apelo, J. A. D. R. N. Appuhamy, and M. D. Hanigan. 2016. Development of a model describing regulation of casein synthesis by the mammalian target of rapamycin (mTOR) signaling pathway in response to insulin, amino acids, and acetate. J. Dairy Sci. 99:6714-6736.

Danfaer, A., I. Thysen, and V. Ostergaard. 1980. The effect of the level of dietary protein on milk production. 1. Milk yield, liveweight gain and health. Beret. Statens Husdyrbrugsfors. 492:107-120.

Ferrell, C. L., H. C. Freetly, A. L. Goetsch, and K. K. Kreikemeier. 2001. The effect of dietary nitrogen and protein on feed intake, nutrient digestibility, and nitrogen flux across the portal-drained viscera and liver of sheep consuming high-concentrate diets ad libitum. J. Anim. Sci. 79:1322-1328.

Hendrickx, J. 2012. Perturb: Tools for Evaluating Collinearity. Vol. R package version 2.05. Accessed Oct. 1, 2016. http://cran.r-project. org/web/packages/perturb/index.html.

Lobley, G. E., A. Connell, M. A. Lomax, D. S. Brown, E. Milne, A. G. Calder, and D. A. H. Farningham. 1995. Hepatic detoxification of ammonia in the ovine liver: Possible consequences for amino acid catabolism. Br. J. Nutr. 73:667-685.

Maltby, S. A., C. K. Reynolds, M. A. Lomax, and D. E. Beever. 2005. Splanchnic metabolism of nutrients and hormones in steers fed alfalfa under conditions of increased absorption of ammonia and L-arginine supply across the portal-drained viscera. J. Anim. Sci. 83:1088-1096.

Martin, A. K., and K. L. Blaxter. 1965. The energy cost of urea synthesis in sheep. Pages 83-91 in Proceedings of the 3rd Symposium on Energy Metabolism. K. L. Blaxter, ed. Academic Press, London, UK.

Maynard, L. A. 1953. Editorial Review: Total digestible nutrients as a measure of feed energy. J. Nutr. 51:15-21.

Milano, G. D., A. Hoston-Moore, and G. E. Lobley. 2000. Influence of hepatic ammonia removal on ureagenesis, amino acid utilization and energy metabolism in the ovine liver. Br. J. Nutr. 83:307-315.

Moraes, L. E., A. B. Strathe, J. G. Fadel, D. P. Casper, and E. Kebreab. 2014. Prediction of enteric methane emissions from cattle. Glob. Chang. Biol. 20:2140-2148.

NRC. 1988. Nutrient Requirements of Dairy Cattle. 6th rev. ed. Nat Acad. Sci., Washington, DC.

NRC. 2001. Nutrient Requirements of Dairy Cattle 7th rev. ed. Natl Acad. Sci., Washington, DC.

Oldham, J. D. 1984. Protein-energy interrelationships in dairy cows. J. Dairy Sci. 67:1090-1114.

Reynolds, C. K., H. F. Tyrrell, and P. J. Reynolds. 1991. Effects of diet forage-to-concentrate ratio and intake on energy metabolism in growing beef heifers: Whole body energy and nitrogen balance and visceral heat production. J. Nutr. 121:994-1003.

Rius, A. G., M. L. McGilliard, C. A. Umberger, and M. D. Hanigan. 2010. Interactions of energy and predicted metabolizable protein in determining nitrogen efficiency in the lactating dairy cow. J. Dairy Sci. 93:2034-2043.

Rojen, B. A., P. K. Theil, and N. B. Kristensen. 2011. Effects of nitrogen supply on inter-organ fluxes of urea-N and renal urea-N kinetics in lactating Holstein cows. J. Dairy Sci. 94:2532-2544.

Roman-Garcia, Y., R. R. White, and J. L. Firkins. 2016. Meta-analysis of postruminal microbial nitrogen flows in dairy cattle. I. Derivation of equations. J. Dairy Sci. 99:7918-7931.

Sinclair, K. D., P. C. Garnsworthy, G. E. Mann, and L. A. Sinclair. 2014. Reducing dietary protein in dairy cow diets: Implications for nitrogen utilization, milk production, welfare and fertility. Animal 8:262-274

Spek, J. W., J. Dijkstra, G. van Duinkerken, W. H. Hendriks, and A. Bannink. 2013. Prediction of urinary nitrogen and urinary urea nitrogen excretion by lactating dairy cattle in northwestern Europe and North America: A meta-analysis. J. Dairy Sci. 96:4310-4322.

St-Pierre, N. R. 2001. Invited review: Integrating quantitative findings from multiple studies using mixed model methodology. J. Dairy Sci. 84:741-755.

Tyrrell, H. F., P. W. Moe, and W. P. Flatt. 1970. Influence of excess protein intake on energy metabolism of the dairy cow. Pages 69-72 in Proceedings of the 5th EAAP Symposium on Energy Metabolism of Farm Animals. A. Schürch and C. Wenk, ed. Juris Verlag, Zurich, Switzerland.

Van Kessel, J. S., and J. B. Russel. 1996. The effect of amino nitrogen on the energetics of ruminal bacteria and its impact on energy spilling. J. Dairy Sci. 79:1237-1243. 